\title{
Multi-parameter analysis of curing cycle for GNPs/glass fabric/ epoxy laminated nanocomposites
}

\author{
Georgios V. Seretis \\ National Technical University of Athens, School of Mechanical Engineering, 15780 Zografou, Athens, Greece \\ ELV ALHALCOR S.A., Copper Tubes Division (HALCOR), 32011, Oinofyta, Viotia, Greece \\ gio.seretis@yahoo.com/gseretis@balcor.com, http://orcid.org/0000-0003-2824-3576 \\ Aikaterini K. Polyzou, Dimitrios E. Manolakos, Christopher G. Provatidis \\ National Technical University of Athens, School of Mechanical Engineering, 15780 Zografou, Athens, Greece \\ k.polyzou@gmail.com; manolako@central.ntua.gr; cprovat@central.ntua.gr
}

\begin{abstract}
In this study, a multi-parameter analysis, using Taguchi method for design of experiments, has been conducted to investigate the optimum curing conditions for GNPs/E-glass fabric/epoxy laminated nanocomposites. The independent variables in the $\mathrm{L}_{25}$ Taguchi orthogonal array were heating rate, curing temperature and curing time, addressing five levels each. Tensile and 3-point bending tests were performed for each experiment number (run number) of the Taguchi $\mathrm{L}_{25}$. The analysis shown that the most significant parameter for tensile strength is the time and for flexural strength is the temperature. Also, it shown that the optimum performance was obtained for temperature values greater than the glass transition temperature $\mathrm{T}_{\mathrm{g}}$.
\end{abstract}

KEYWORDS. Polymer-matrix composites; Nanocomposites; Graphene nanoplatelets; Curing; Mechanical testing; Multi-parameter analysis.

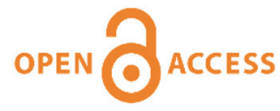

Citation: Seretis, G.V., Polyzou, A.K., Manolakos, D.E., Provatidis, C.G., Multi-parameter analysis of curing cycle for GNPs/glass fabric/ epoxy laminated nanocomposites, Frattura ed Integrità Strutturale, 50 (2019) 517-525.

Received: 19.01 .2019

Accepted: 22.05.2019

Published: 01.10.2019

Copyright: (C) 2019 This is an open access article under the terms of the CC-BY 4.0, which permits unrestricted use, distribution, and reproduction in any medium, provided the original author and source are credited.

\section{INTRODUCTION}

\footnotetext{
$\mathrm{C}$ omposites of epoxy matrix are of the most commonly used polymer matrix composites. For this kind of composites several different types of reinforcement have been tested. However, the reinforcing material is not the only significant factor for the final properties of the produced epoxy matrix composites. The curing process, due to the great number of properties it affects or controls [1,2], also plays a key role. For this reason, to accurately control the results of a curing process, it is necessary to understand the effects of all the affecting parameters. Therefore, the parameters which are known to affect a curing process, such as curing temperature and time, have been widely investigated [3-10]. For example, the relation between the curing temperature $\left(\mathrm{T}_{\text {cure }}\right)$ and the glass transition temperature $\left(\mathrm{T}_{\mathrm{g}}\right)$ has been found to controls the applied curing mechanism and, therefore, it is of great importance [11]. Also, related research works have been focused on alternative curing processes [12-14], such as curing using microwaves.
} 
Taguchi analysis is widely used in the research of composite materials. For example, it is used to investigate the influence of surface treatment on the composites' performance [15] and the importance of V-ring indenter parameters [16], to determine the optimum machining conditions leading to minimum surface roughness in drilling of GFRP composite [17], to develop multiphase hybrid epoxy matrix composites reinforced with glass-fiber and filled with rice husk particulates [18], etc. Analysis of Variance (ANOVA) and Regression or Multiple Regression models regularly follow the Taguchi method to create an effective prediction model. The commonly used Multiple Regression models [16,17] are not always able to achieve high accuracy in prediction. Therefore, researchers started working on more accurate multiple regression models [19,20].

In this study, a multi-parameter analysis, using Taguchi method for design of experiments, has been conducted to investigate the optimum curing conditions for GNPs/E-glass fabric/epoxy laminated nanocomposites. The independent variables in the $\mathrm{L}_{25}$ Taguchi orthogonal array were heating rate, curing temperature and curing time, addressing five levels each. Tensile and 3-point bending tests were performed for each experiment number (run number) of the Taguchi $\mathrm{L}_{25}$. According to the analysis of variance, the significant parameter for tensile performance was the curing time and for flexural performance was the curing temperature, at a 95\% confidence level. The Full Quadratic regression model was used to predict the tensile response of the nanocomposites, since the respective main effects plots were more linear or shown clear trends. On the other hand, for the flexural performance, where the respective main effects plots neither were linear nor shown clear trends, the Poisson regression model was used to achieve high accuracy in prediction. The $\mathrm{R}^{2}$ of the regression models used was greater than $90 \%$ for the prediction of both tensile and flexural values.

\section{EXPERIMENTAL PROTOCOL}

\section{Materials}

he matrix material used for the nanocomposite specimens was the low-viscosity Araldite GY 783 epoxy resin together with the low-viscosity, phenol free, modified cycloaliphatic polyamine hardener. The glass transition temperature $(\mathrm{Tg})$ was $100^{\circ} \mathrm{C}$ and the gel time for the specific matrix composition at $20^{\circ} \mathrm{C}$ and $65 \%$ relative humidity $(\mathrm{RH})$, conditioning requirements which were obeyed during the preparation of the nanocomposites laminates, was 35 min. Woven E-glass fabric of $282 \mathrm{~g} / \mathrm{m}^{2}$ density was used for matrix reinforcement, as presented in Fig.1. Table 1 presents the characteristics of the fabric used. The warp direction is the enhanced one, as can be seen in, and therefore it was the main weave direction. Thus, the laminae orientations in the stacking sequence of the composites will be based on the warp direction. Graphene nanoplatelets (GNPs) by Alfa Aesar of surface area (S.A.) $500 \mathrm{~m}^{2} / \mathrm{g}$ were also used as filler material.

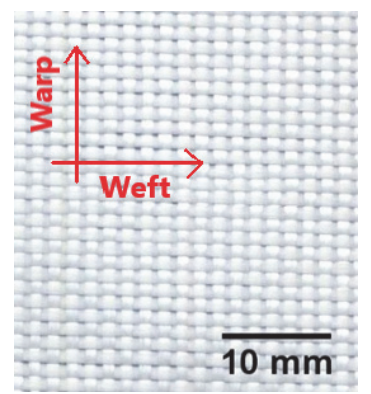

Figure 1: The woven E-glass fabric used in positioning angle (layer orientation) $0^{\circ}$.

\begin{tabular}{lcc}
\hline Characteristics & Warp & Weft \\
Fiber description & Glass EC11 204 fiber & Glass EC11 204 fiber \\
Thread count (ends $/ \mathrm{cm})$ & 8 & 6 \\
Weight distribution $(\%)$ & 57 & 43 \\
\hline
\end{tabular}

Table 1: E-glass fabric's characteristics.

Preparation of E-glass fabric/ epoxy laminated composites

To prepare the GNPs-reinforced matrix, weighed amount of pre-dried graphene nanoplatelets were stirred gently into the epoxy resin using a laboratory mixer for mechanical stirring for a process time of 25 min at $200 \mathrm{rpm}$, to ensure homogeneity of the suspension [22]. Weighed amount of hardener was added into the GNPs reinforced epoxy resin mixture at the manu- 
facturer recommended resin/hardener proportion, which was a 100:50 by weight ratio, and stirred gently using a laboratory mixer for mechanical stirring for a process time of $5 \mathrm{~min}$ at $200 \mathrm{rpm}$. Subsequently, the matrix mixture was coated and handrolled on E-glass fabrics in layer sequence under constant stirring [22-25]. For each hand lay-up procedure, four layers of E-glass fabric were employed in $\left[0^{\circ} / 45^{\circ} /-45^{\circ} / 0^{\circ}\right]_{\mathrm{T}}$ sequence. The GNPs w.t. contents used for UD laminates reinforcement were $5 \%$. The selection of the GNPs content was made based on literature on the content that provides the best performance of the specific nanocomposites [22]. Before the first layer coating, the surface on which the specimens were produced was covered by release paste wax. The hand lay-up procedure applied is well-known and has been presented in explosive view mode in other published works [22,23]. To achieve a $40 \pm 1 \%$ by volume epoxy proportion in all specimens, both the fabric and the matrix mixture used for coating were weighed before each hand lay-up process and after solidification.

\section{Curing cycle}

All specimens left in ambient temperature for 6 hours before the curing conditions of the Taguchi design of experiments were applied. Therefore, the complete curing cycle applied is presented in Fig.2, where parameter $a$, $T_{1}$ and $b_{1}$ represent the heating rate $\left[{ }^{\circ} \mathrm{C} / \mathrm{min}\right]$, the temperature of the first curing step $\left[{ }^{\circ} \mathrm{C}\right]$ and the duration of the first curing step $[\mathrm{h}]$, respectively. The selected values for each parameter under study (i.e. the design of experiment levels) can be found in Table 2.

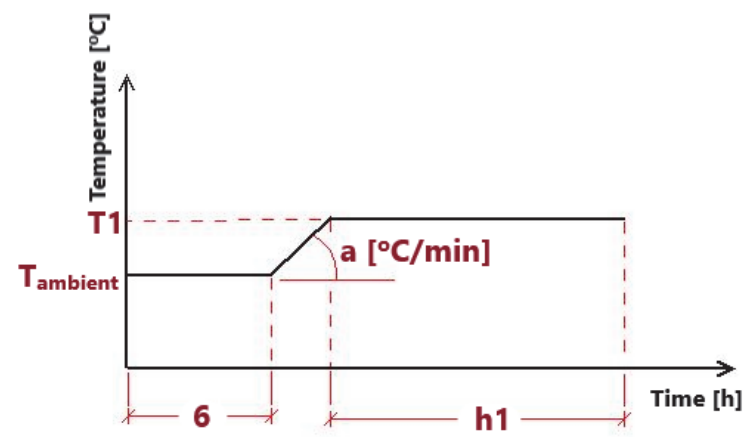

Figure 2: The curing cycle applied with the parameters of the Taguchi design of experiments noted.

\begin{tabular}{lccccc}
\hline Control factor & 1 & 2 & 3 & 4 & 5 \\
A: Heating Rate $\left[{ }^{\circ} \mathrm{C} / \mathrm{min}\right]$ & 1 & 2 & 3 & 4 & 5 \\
B: Temperature $\left[{ }^{\circ} \mathrm{C}\right]$ & 50 & 80 & 100 & 120 & 140 \\
C: Time $[\mathrm{h}]$ & 2 & 4 & 6 & 8 & 10 \\
\hline
\end{tabular}

Table 2: Design of Experiments (DOE) factors and their levels.

The curing temperature $\left(T_{\text {cure }}\right)$ can be either higher or lower of the glass transition temperature $\left(T_{g}\right)$ [3-5,22-25]. When $T_{\text {cure }}>T_{g}$, the reaction proceeds rapidly at a rate driven by chemical kinetics. When $T_{\text {cure }}=T_{g}$, vitrification takes place (i.e., material solidifies). Finally, when $T_{\text {cure }}<T_{g}$, the reaction rate decelerates and becomes diffusion-controlled. To include all these mechanisms in the Taguchi design of experiments, apart from the $T_{g}$ temperature, two different temperatures both under and over $T_{g}$ were selected as presented in Table 2 .

The dimensions of each specimen which underwent 3-point bending tests were $93.6 \times 12.7 \times 1.1 \mathrm{~mm}$, according to the ASTM D790-03 test method. The specimens which underwent tensile test had a total size of $102 \times 6 \times 1.1 \mathrm{~mm}$ in accordance with ASTM D3039/3039M. All specimens were cut at their testing dimensions using a Struers Discotom-2 along with a 40A25 cut-off wheel. To evaluate if tabs were needed on the holding regions of the specimens, the theoretical tab limits were marked on the specimens, as indicated from the above ASTM standard method [22,23]. Since the failure occurred into the theoretical control region no tabs are recommended by the ASTM standard used.

For each experiment number (run number) of the Taguchi design of experiments, five specimens were prepared and underwent each test (five specimens for each tensile and five for each flexural test).

Experimental set-up and tests

An Instron 4482 test machine of $100 \mathrm{kN}$ capacity was used for the both tensile and 3-point bending tests. In accordance with the ASTM standard methods D790-03 and D3039/3039M, all tests were performed in a standard laboratory atmo- 
sphere $\left(23 \pm 1^{\circ} \mathrm{C}\right.$ and $50 \pm 5 \%$ relative humidity). Test conditioning was kept constant for 6 hours before each test. To meet the test method's span-to-depth specification, the support span was set at $52 \mathrm{~mm}$ for the flexural tests. The recommended from the ASTM methods test speed of $2 \mathrm{~mm} / \mathrm{min}$ was applied on both tensile and 3-point bending tests.

\section{Taguchi design of experiments}

Taguchi's method uses a special design of orthogonal arrays to study the entire process parameter space with just a small number of experiments. Using Taguchi's method the number of experiments to evaluate the influence of control parameters on certain quality properties or characteristics is considerably reduced as compared to a full factorial approach [23,24].

There are three ways of transformation to calculate the loss function, depending on the desired characteristic of the measured value. The characteristic of the desired value can either be the-lower-the-better, the-higher-the-better or thenominal-the better. The loss function of the "the-higher-the-better" quality characteristic $\left(y_{k}\right)$, which was used for this study, with $\mathrm{m}$ as the mean of the target quality parameter is calculated as shown in Eq.(1) where $L_{i j}$ is the loss function of the $i_{\text {th }}$ performance characteristic in the $j_{\text {th }}$ experiment $[23,24]$.

$$
L_{i j}=\frac{1}{n} \sum_{k=1}^{n} \frac{1}{y_{i j}{ }^{2}}
$$

In the Taguchi method, the $S / N$ ratio $n_{\mathrm{ij}}$ for the $i_{\text {th }}$ performance characteristic in the $j_{\text {th }}$ experiment, which can be calculated using Eq.(2), is used to determine the deviation of the performance characteristic from the desired [23,24]:

$$
n_{i j}=-10 \log \left(L_{i j}\right)
$$

Regardless of the category of the performance characteristic, a larger $S / N$ ratio indicates a performance of a better quality. Therefore, the optimal level of the process parameters is the level with the highest $S / N$ ratio.

The selection of control factors is the most important step in a design of experiments. It is known that heating rate $(a)$, temperature $\left(T_{1}\right)$, time $\left(t_{1}\right)$ are three factors which affect the mechanical behavior of an epoxy matrix and, consequently, of a laminated composite $[23,24]$. Therefore, it is expected that these three factors also affect the mechanical behavior in the case of epoxy matrix nanocomposites. In this work, the impact of these three factors on tensile and flexural strength of GNPs/glass fabric/epoxy laminated nanocomposites is studied using an $L_{25}$ orthogonal array design. The selected levels of the three control factors are presented in Table 2.

\section{ANALYSIS OF VARIANCE (ANOVA)}

A

nalysis of variance (ANOVA) is a statistical tool which examines the hypothesis that the means of two or more populations are equal and, subsequently, it evaluates the significance of one or more factors, by comparing the response variable means at the different factor levels. The significant factors for both tensile and flexural performance were temperature and time in this study, at 95\% confidence level (see Tables 3 and 4). Specifically, the tensile performance is mostly affected by curing time $(31.18 \%)$. On the other hand, the flexural performance is mostly affected by curing temperature $(32.67 \%)$ and secondarily by curing time $(18.32 \%)$. The main effects plot for the main effect terms in ultimate tensile strength (UTS) and flexural strength for factors a, $T_{1}$, and $t_{1}$ are shown in Figs. 3 and 4, respectively. Additional tests were conducted to confirm the results of the above analysis (see Tables 5 and 6). The error achieved was lower than 1\% in both cases. The optimal values can be predicted using Eq.(3) [23,24].

$$
n_{\text {opt }}=n_{m}+\sum_{i=1}^{q}\left(n_{i}-n_{m}\right)
$$

where: $n_{m}$ is the total mean of the response (UTS and flexural strength, respectively) and characteristic under consideration; $n_{i}$ is the mean values at the optimum level and $q$ is the number of control factors that significantly affects curing process of composite.

\section{Results and discussion}

The main effects plot for the main effect terms in UTS for factors $a, T_{1}, h_{1}$ are shown in Fig.3. From the main effect plots, it has been observed that the UTS of the composite significantly increase for temperature increase from $50{ }^{\circ} \mathrm{C}$ to $80^{\circ} \mathrm{C}$. Temperature increase up to $120^{\circ} \mathrm{C}$ does not cause any change in the tensile performance, while further increase again increases 


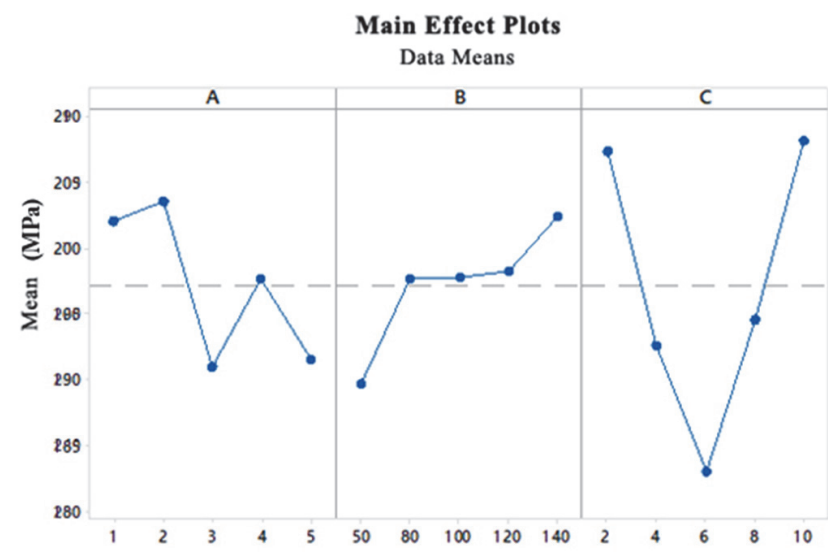

Figure 3: Main effect plots for UTS for $a, T_{1}$ and $b_{1}$ factors.

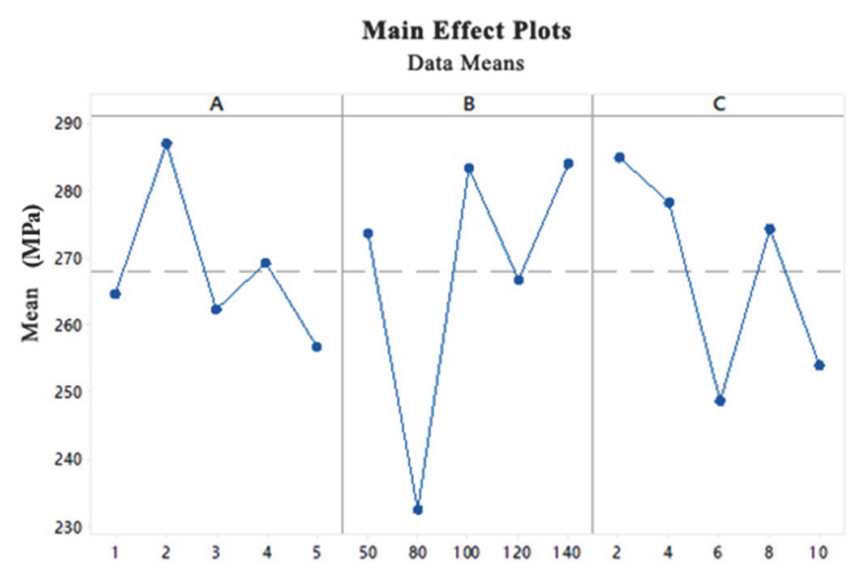

Figure 4: Main effect plots for flexural strength for $a, T_{1}$ and $h_{1}$ factors.

\begin{tabular}{ccccccc}
\hline Source & $\mathrm{dF}$ & Sum of squares & Mean square & F-value & P value & $\mathrm{C}(\%)$ \\
A: Heating Rate $\left[{ }^{\circ} \mathrm{C} / \mathrm{min}\right]$ & 4 & 661.7 & 165.4 & 0.51 & 0.73 & 9.23 \\
B: Temperature $\left[{ }^{\circ} \mathrm{C}\right]$ & 4 & 423,2 & 105,8 & 0.31 & 0.865 & 5.9 \\
C: Time $[\mathrm{h}]$ & 4 & 2235 & 558.6 & 2.26 & 0.098 & 31.18 \\
\hline
\end{tabular}

Table 3: ANOVA results for tensile tests without interaction, * Significant at $95 \%$ confidence level.

\begin{tabular}{ccccccc}
\hline Source & $\mathrm{dF}$ & Sum of squares & Mean square & F-value & P value & $\mathrm{C}(\%)$ \\
A: Heating Rate $\left[{ }^{\circ} \mathrm{C} / \mathrm{min}\right]$ & 4 & 2644 & 661 & 0.54 & 0.711 & 9.68 \\
B: Temperature $\left[{ }^{\circ} \mathrm{C}\right]$ & 4 & 8925 & 2231.2 & 2.43 & 0.082 & 32.67 \\
C: Time $[\mathrm{h}]$ & 4 & 5004 & 1251 & 1.12 & 0.374 & 18.32 \\
\hline
\end{tabular}

Table 4: ANOVA results for flexural tests without interaction, ${ }^{*}$ Significant at $95 \%$ confidence level.

\begin{tabular}{ccc}
\hline Parameter & \multicolumn{2}{c}{ Optimal Parameters } \\
& \multicolumn{2}{c}{$\mathrm{A}_{3} \mathrm{~B}_{5} \mathrm{C}_{1}$} \\
& Experimental & Predicted \\
UTS $(\mathrm{MPa})$ & 214.65 & 218.848 \\
Error $\%$ & \multicolumn{3}{c}{$1.95 \%$} \\
\hline
\end{tabular}

Table 5: Confirmation table for optimum tensile performance. 


\begin{tabular}{ccc}
\hline Parameter & \multicolumn{2}{c}{ Optimal Parameters } \\
& \multicolumn{2}{c}{$\mathrm{A}_{2} \mathrm{~B}_{5} \mathrm{C}_{1}$} \\
& Experimental & Predicted \\
Flexural Strength (MPa) & 285 & 278.007 \\
Error \% & \multicolumn{2}{c}{$2.45 \%$} \\
\hline
\end{tabular}

Table 6: Confirmation table for optimum flexural performance.

the tensile performance of the nanocomposites. It seems that the nanofillers act like cooling points within the epoxy matrix, negating in this manner the previously reported negative effect of temperature increase on E-glass fabric/ epoxy composite specimens' performance. The heating rate, when it increases from $1{ }^{\circ} \mathrm{C} / \mathrm{min}$ to $2^{\circ} \mathrm{C} / \mathrm{min}$, results in a slight tensile increase, while greater increase of its value tend to decrease the tensile performance of the material. Specifically, for heating rate values ranging from $2^{\circ} \mathrm{C} / \mathrm{min}$ to $3^{\circ} \mathrm{C} / \mathrm{min}$ a significant performance drop can be observed. Subsequently, for heating rate value increase up to $4^{\circ} \mathrm{C} / \mathrm{min}$ the tensile performance slightly increases and for further increase of a it decreases again. Overall, for heating rate values greater than $2^{\circ} \mathrm{C} / \mathrm{min}$ the UTS values are considerably low. The curing time increase up to 6 hours leads to a consequent significant performance drop. However, for further curing time increase, up to 10 hours, the tensile performance increases again, overpassing the performance that corresponds to a curing time equal to 2 hours.

The main effects plot for the main effect terms in flexural strength for factors $a, T_{1}$, and $b_{1}$ are shown in Fig.4. The heating rate increase leads to an initial flexural performance increase, for heating rate value increase from $1{ }^{\circ} \mathrm{C} / \mathrm{min}$ to $2^{\circ} \mathrm{C} / \mathrm{min}$, and subsequently, for further increase of the heating rate value, to a flexural performance drop. Slight curing temperature increase, i.e. from $50^{\circ} \mathrm{C}$ to $80^{\circ} \mathrm{C}$, dramatically decrease the flexural strength of the material. Further temperature increase causes a consequent increase in flexural performance. A progressive increase of the curing time significantly decreases the flexural strength of the material.

\section{MULTIPLE REGRESSION ANALYSIS}

The

he above analysis was followed by a regression analysis, which was applied to create a model for prediction of the performance of the nanocomposites as regards both tensile and flexural performance. The commonly used full quadratic regression model, involving only the main factors as they occurred from the ANOVA analysis, achieved significantly low prediction accuracy in the case of the nanocomposite materials (about $62 \%$ ). Due to the low accuracy of this regression model led to the necessity for a more leviable and accurate regression model. Therefore, a Poisson regression model was used to improve the prediction accuracy for the flexural performance and the full quadratic regression model enhanced with the interaction between the second order terms (modified full quadratic model) was used for tensile performance prediction. The accuracy of these models was $94.9 \%$ and $90.99 \%$, respectively. The backwards elimination method was applied again on all the parameters included in the regression. The $F_{\text {out }}$ factor for terms removal was selected equal to 4. All three curing process parameters selected were considered as independent variables. Therefore, two different regression models were created, i.e. a Poisson regression model for the flexural performance prediction and a modified full quadratic regression model for the tensile performance prediction of the nanocomposites. These two regression models are presented in Eqs.(4) and (5), respectively.

$$
\text { Flexural Strength }=e^{Y_{3}^{\prime}}
$$

where

$$
\begin{aligned}
Y_{3}^{\prime}=6.09-4.10 & \times a+0.0054 \times T_{1}+4.703 \times h_{1}-1.105 \times a^{2}-0.001897 \times T_{1}{ }^{2}-0.12 \times h^{2} \\
& +0.063 \times a \times T_{1}-0.841 \times a \times h_{1}-0.03293 \times T_{1} \times h_{1}+0.33 \times a^{3}+0.00001 \times T_{1}{ }^{3} \\
& +0.0401 \times h_{1}{ }^{3}+0.0914 \times a^{2} \times h_{1}+0.0001 \times a \times T_{1}{ }^{2}-0.001283 \times a \times h_{1} \times T_{1} \\
& -0.01888 \times a^{4}-0.001775 \times h_{1}{ }^{4}-0.01132 \times a^{3} \times h_{1}
\end{aligned}
$$

Tensile Strength $=Y_{4}^{\prime}$

where 


$$
\begin{aligned}
Y_{4}^{\prime}=407-166 & \times a-10.29 \times T_{1}+2.4 \times h_{1}+55.8 \times a^{2}+0.0491 \times T_{1}{ }^{2}-19.22 \times h^{2}+11.77 \times a \times T_{1} \\
& -84.7 \times a \times h_{1}+1.399 \times T_{1} \times h_{1}-2.403 \times a^{2} \times T_{1}+18.51 \times a^{2} \times h_{1}-0.0654 \times a \times T_{1}{ }^{2} \\
& +9.31 \times a \times h_{1}{ }^{2}+0.01051 \times a^{2} \times T_{1}{ }^{2}-1.597 \times a^{2} \times h_{1}{ }^{2}
\end{aligned}
$$

\section{Results and discussion}

Fig.5 presents the performance of the modified full quadratic regression model used for the tensile performance prediction. Fig.6 presents the performance of the Poisson regression model used for the flexural performance prediction. The above results when compared to the respective ones for laminated composites without GNPs reinforcement [23], lead to the conclusion that the GNPs reinforcement does not affect which is the most significant parameter for both tensile and flexural performance. Thus, for the tensile performance of the specific composites, with and without GNPs reinforcement, the most significant parameter is the curing time and for the flexural performance the curing temperature.

However, in the case of GNPs reinforced nanocomposites, the less significant parameter for the tensile performance is temperature, when the respective one for the composites without GNPs reinforcement is heating rate [23]. This may be related to the significantly different thermal expansion coefficient between matrix, fibers and graphene nanoparticles [25].

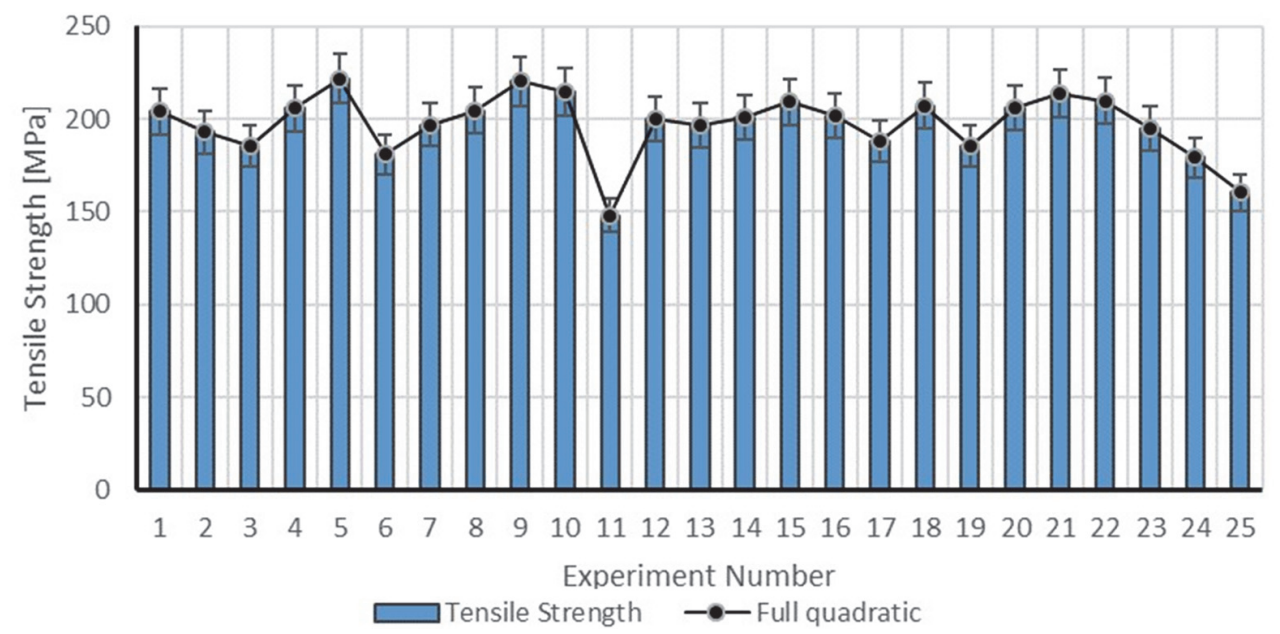

Figure 5: Experimental and theoretical values of tensile strength (calculated using the modified full quadratic regression model).

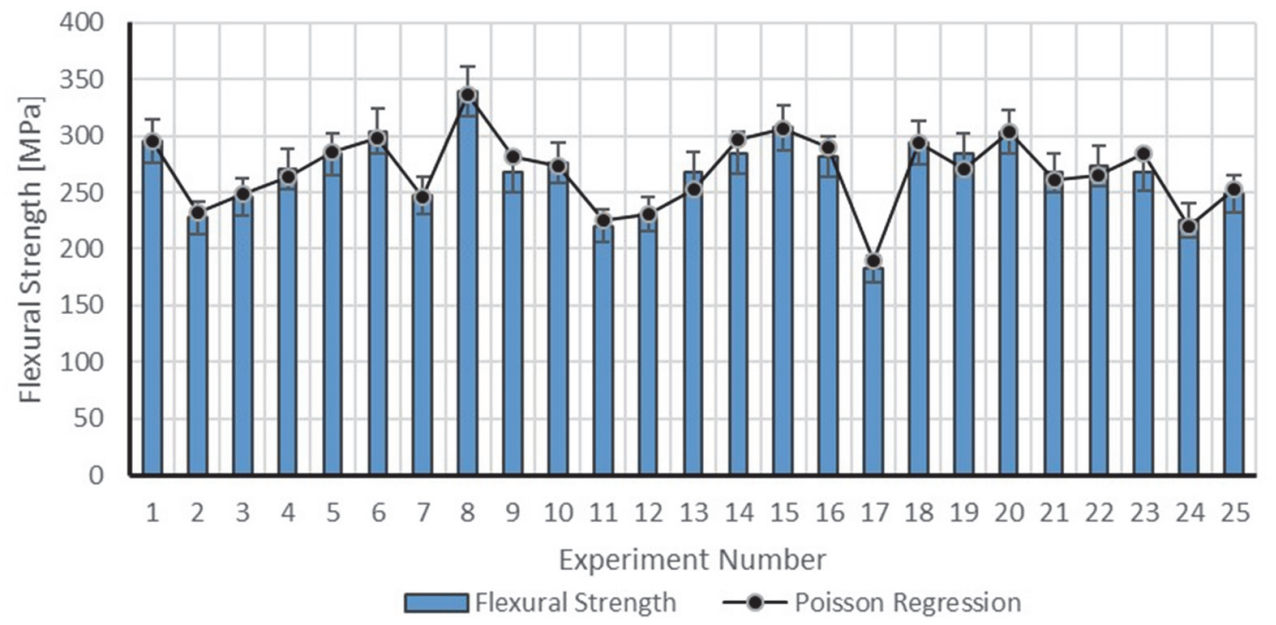

Figure 6: Experimental and theoretical values of flexural strength (calculated using the Poisson regression model).

\section{CONCLUSIONS}

NPs/woven E-glass fabric/epoxy laminated nanocomposites were produced using a hand lay-up process and underwent tensile and flexural testing according to a $L_{25}$ Taguchi design of experiments. Based on the experimental results as well as the subsequent statistical analysis, the following remarks may be drawn: 
(a) The most significant parameter for tensile strength is the time and for flexural strength is the temperature. Therefore, for slow temperature increase values, i.e. $1-5^{\circ} \mathrm{C} / \mathrm{min}$, the effect of the heating rate on both the tensile and the flexural performance of the cured laminated nanocomposites is not considerable.

(b) The optimum performance was obtained for temperature values greater than the glass transition temperature $T_{g}$. It is known that when $T_{\text {cur }}>T_{g}$, the reaction proceeds rapidly at a rate driven by chemical kinetics. Therefore, it is obvious that both tensile and flexural performance of the epoxy matrix laminated nanocomposites is mainly controlled by the chemical kinetics.

(c) The Full Quadratic regression model was used to predict the tensile response of the nanocomposites, since the respective main effects plots were more linear or shown clear trends. On the other hand, for the flexural performance, where the respective main effects plots neither were linear nor shown clear trends, the Poisson regression model was used to achieve high accuracy in prediction.

\section{REFERENCES}

[1] Gao, L., Zhang, Q., Guo, J., Li, H., Wu, J., Yang, X., Sui, G. (2016). Effects of the amine/epoxy stoichiometry on the curing behavior and glass transition temperature of MWCNTs-NH2/epoxy nanocomposites, Thermochim Acta, 639, pp. 98-107.

[2] Fu, Y., Zhong, W.H. (2011). Cure kinetics behavior of a functionalized graphitic nanofiber modified epoxy resin, Thermochim Acta, 516, pp. 58-63.

[3] Ellis, B. (1993). Chemistry and Technology of Epoxy Resins, London, New York: Blackie Academic \& Professional, An imprint of Chapman \& Hall.

[4] Wisanrakkit, G., Gillham, J.K. (1990). Glass transition temperature (Tg) as an index of chemical conversion for highTg amine/epoxy system: chemical and diffusion controlled reaction kinetics, J. Appl. Polymer Sci., 41(11-12), pp. 2885-2929.

[5] Moussa, O., Vassilopoulos, A.P., Castro, J., Keller, T. (2012). Time temperature dependence of thermomechanical recovery of cold-curing structural adhesives, Int. J. Adhes. Adhes.,35, pp. 94-101.

[6] Maljaee, H., Ghiassi, B., Lourenço, P.B. (2017). Effect of synergistic environmental conditions on thermal properties of a cold curing epoxy resin, Compos. Part B-Eng., 113, pp. 152-163.

[7] Chang, C.Y., Houang, L.W., Chou, T.Y. (2006). Effect of process variables on the quality of compression resin transfer molding, J. Reinf. Plast. and Comp., 25, pp. 1027-1037.

[8] Oh, J.H., Lee, D.G. (2002). Cure cycle for thick glass/epoxy composite laminates, J. Comp. Mat., 36, pp. 19-44.

[9] Rai, N., Pitchumani, R. (1997). Optimal cure cycles for the fabrication of thermosetting matrix composites, Polym. Compos. 18(4), pp. 566-81.

[10] Li, M., Zhu, Q., Geubelle, P.H., Tucker III, C.L. (2001). Optimal curing for thermoset matrix composites: thermochemical considerations, Polym. Compos., 22(1), pp. 118-31.

[11] Moussa, O., Vassilopoulos, A.P., Keller, T. (2012). Effects of low-temperature curing on physical behavior of coldcuring epoxy adhesives in bridge construction, Int. J, Adhes. Adhes. 32, pp. 15-22.

[12] Mijovic, J., Fishbain, A., Wijaya, J. (1992). Mechanistic modeling of epoxy amine kinetics. 2. Comparison of kinetics in thermal and microwave fields, Macromolecules, 25, pp. 986-989.

[13] Kwak, M., Robinson, P., Bismarck, A., Wise, R. (2015). Microwave curing of carbon-epoxy composites: Penetration depth and material characterization, Compos. Part A-Appl. S., 75, pp. 18-27.

[14] Johnston, K., Pavuluri, S.K., Leonard, M.T., Desmulliez, M.P.Y., Arrighi, V. (2015). Microwave and thermal curing of an epoxy resin for microelectronic applications, Thermochim Acta, 616, pp. 100-109.

[15] Barbosa, A.Q., da Silva, L.F.M., Abenojar, J., Figueiredo, M., Ochsner, A. (2017). Toughness of a brittle epoxy resin reinforced with micro cork particles: Effect of size, amount and surface treatment, Compos. Part B-Eng., 114, pp. 299-310.

[16] Thipprakmas, S. (2010). Application of Taguchi technique to investigation of geometry and position of V-ring indenter in fine-blanking process, Mater. Des., 31, pp. 2496-2500.

[17] Parida, A.K., Routara, B.C., Bhuyan, R.K. (2015). Surface roughness model and parametric optimization in machining of GFRP composite: Taguchi and Response surface methodology approach, Materials Today: Proceedings, 2, pp. 30653074.

[18] Rout, A.K., Satapathy, A. (2012). Study on mechanical and tribo-performance of rice-husk filled glass-epoxy hybrid composites, Mater. Des. 41, pp. 131-141. 
[19] Guo, H., Wang, X., Gao, Z. (2017). Uncertain linear regression model and its application, J. Intell. Manuf., 28, pp. 559. DOI: $10.1007 / \mathrm{s} 10845-014-1022-4$

[20] Tangjitsitcharoen, S., Thesniyom, P., Ratanakuakangwan, S. (2017). Prediction of surface roughness in ball-end milling process by utilizing dynamic cutting force ratio, J. Intell. Manuf., 28, pp.13. DOI: 10.1007/s10845-014-0958-8

[21] Li, H., Wang, Y., Zhao, P., Zhang, X., Zhou, P. (2015). Cutting tool operational reliability prediction based on acoustic emission and logistic regression model, J. Intell. Manuf. 26(5), pp. 923-931. DOI: 10.1007/s10845-014-0941-4

[22] Seretis, G.V., Kouzilos, G., Manolakos, D.E., Provatidis, C.G. (2017). On the graphene nanoplatelets reinforcement of hand lay-up glass fabric/epoxy laminated composites, Compos. Part B-Eng. 118, pp. 26-32.

[23] Seretis, G.V., Kouzilos, G., Manolakos, D.E., Provatidis, C.G. (2018). Multi-Objective Curing Cycle Optimization for Glass Fabric/Epoxy Composites Using Poisson Regression and Genetic Algorithm, Mater. Research, DOI: $10.1590 / 1980-5373-\mathrm{mr}-2017-0815$

[24] Seretis, G.V., Kouzilos, G., Manolakos, D.E., Provatidis, C.G. (2018). Multi-objective optimization of post-curing process for gnps reinforced glass fabric/epoxy nanocomposite laminae. Polym. Compos.. DOI: 10.1002/pc.24777

[25] Seretis, G.V., Nitodas, S.F., Mimigianni, P.D., Kouzilos, G., Manolakos, D.E., Provatidis, C.G. (2018). On the postcuring of graphene nanoplatelets reinforced hand lay-up glass fabric/epoxy nanocomposites, Compos. Part B-Eng., 140, pp. $133-138$ 